\title{
Influência da Fase Sigma na Resistência à Cavitação em Solda de Reparo de Aço Inoxidável Austenítico AISI 309L
}

\author{
Israel Ricardo de Lima ${ }^{1}$, Silvio Francisco Brunatto ${ }^{2}$ (), Sérgio Luiz Henke² ${ }^{\circ}$ \\ ${ }^{1}$ Universidade Federal do Paraná - UFPR, Programa de Pós-Graduação em Engenharia Mecânica, Curitiba, PR, Brasil.
}

${ }^{2}$ Universidade Federal do Paraná - UFPR, Departamento de Engenharia Mecânica, Curitiba, PR, Brasil.

Como citar: Lima IR, Brunatto SF, Henke SL. Influência da fase sigma na resistência à cavitação em solda de reparo de aço inoxidável austenítico aisi 309I. Soldagem \& Inspeção. 2021; 26; e2611. https://doi.org/10.1590/0104-9224/SI26.11

\begin{abstract}
Resumo: $O$ reparo por soldagem de regiões erodidas por cavitação em rotores de turbinas hidráulicas é muitas vezes realizado utilizando como metal de adição o aço inoxidável austenítico AISI 309L. Ciclos térmicos provenientes dos sobrepasses, bem como a realização de tratamento térmico de alívio de tensão após a soldagem, induzem a formação de fase sigma na microestrutura do material depositado. Neste trabalho são apresentados resultados de ensaios de cavitação realizados conforme a norma ASTM G32-10 obtidos em depósitos de soldas do aço AISI 309L, com e sem fase sigma resultante de tratamentos térmicos. Os resultados do ensaio de cavitação revelaram que a fase sigma ocasionou a redução de $78 \%$ do período de incubação e o aumento de $30 \%$ da taxa de erosão máxima em comparação ao material sem esta fase. Infere-se que a redução do período de incubação estaria, a princípio, relacionada a diferenças de propriedades mecânicas entre a fase sigma e a matriz austenítica. Por outro lado, constatou-se que a taxa de erosão máxima seria resultante da presença da fase sigma a qual promoveu a redução da tenacidade do material.
\end{abstract}

Palavras-chave: Aço inoxidável austenítico; Fase sigma; Cavitação.

\section{Sigma Phase Influence on Cavitation Damage in AISI 309L Austenitic Stainless Steel Weld Repair}

\begin{abstract}
Welding repair of cavitation damage in hydraulic turbine runners can be carried out using $309 L$ austenitic stainless steel. Thermal cycles produced by the subsequent passes as well as the stress relief heat treatment after welding induce sigma phase precipitation in the weld microstructure. In this work results of cavitation tests performed according to the ASTM G32-10 standard obtained in weld deposits of AISI 309L steel, with and without sigma phase resulting from heat treatments, are presented. Cavitation test revealed that sigma phase caused a $78 \%$ reduction in the incubation period and a $30 \%$ increase in the maximum erosion rate compared to the material without this phase. It is inferred that the reduction in the incubation period would, in principle, be related to differences in mechanical properties between the sigma phase and the austenitic matrix. On the other hand, it was found that the maximum erosion rate would be the result of the presence of the sigma phase, which promoted a reduction in the toughness of the material.
\end{abstract}

Keywords: Austenitic stainless steel; Sigma phase; Cavitation.

\section{Introdução}

Segundo a Agência Nacional de Energia Elétrica - ANEEL [1], atualmente no Brasil, cerca de 109 GW, o equivalente a 62\% da energia total gerada no país, é proveniente de fonte hídrica. Tal produção classifica o país como sendo o segundo maior produtor mundial a utilizar esta fonte de energia ficando apenas atrás da China (356 GW) e a frente dos Estados Unidos (103 GW) [2].

Nas centrais hidrelétricas, o desgaste por cavitação sobre a superfície dos componentes de turbinas hidráulicas, em particular os rotores, além de influenciar no desempenho deste tipo de equipamento, induz a necessidade periódica de serem efetuados reparos por soldagem das áreas cavitadas [3]. Tais reparos resultam não só na indisponibilidade temporária do fornecimento de energia da unidade geradora mas também na introdução de defeitos e tensões residuais sobre o material dos rotores culminando muitas vezes no surgimento de trincas por fadiga ou até mesmo na fratura catastrófica de suas pás. Destacase que a indisponibilidade da unidade geradora contribui no aumento da tarifa, haja vista a necessidade de compensar o fornecimento de energia com outras fontes energéticas de maior custo.

Os rotores das turbinas hidráulicas utilizados na geração de energia são fabricados em sua maioria por fundição utilizando aços inoxidáveis martensíticos e, devido à alta temperabilidade de tais aços, existe razoável risco da ocorrência de trincas por hidrogênio na zona termicamente afetada (ZTA) produzida pela soldagem [4,5]. De forma a minimizar tal risco, opta-se por efetuar tais reparos utilizando como metal de adição aços inoxidáveis da classe austenítica e, quando possível, a realização de 
tratamento térmico de alívio de tensões após a soldagem [4,5]. Dentre as composições austeníticas usualmente empregadas que atendem aos requisitos de soldabilidade e desempenho frente à cavitação, encontra-se a liga AISI 309L, cuja microestrutura desenvolvida após a soldagem é constituída em sua maioria por austenita e certa quantidade de ferrita delta.

Segundo a literatura [4,5] a presença da ferrita delta entre 5 e $10 \%$ no metal de solda dos aços inoxidáveis austeníticos se faz necessária de forma a minimizar a probabilidade da ocorrência de trincas de solidificação. Tal afirmação é justificada com base na maior solubilidade de impurezas como fósforo e enxofre junto à fase ferrítica em relação à austenítica, evitando-se, assim, a formação de compostos de baixo ponto de fusão nos contornos de grão da austenita. No entanto, quando exposta à temperaturas entre 600 e $850^{\circ} \mathrm{C}$, a ferrita delta tende a se transformar em fase sigma. Como sabido, a fase sigma é considerada indesejável por induzir a uma elevada fragilidade e a uma mais baixa resistência à corrosão no material ou liga base em que a mesma se encontra presente ou é formada [6-9]. Destaque-se ainda a possibilidade de formação de fase sigma em decorrência da ciclagem térmica proveniente dos sobrepasses durante a soldagem [9].

Zakrzewska e Krella [10] apresentam a influência das propriedades mecânicas bem como da microestrutura na resistência à cavitação de diferentes materiais metálicos. Segundo estes autores, materiais contendo microestrutura de granulação fina e homogênea além de alta tenacidade e elevada resistência à fadiga tendem apresentar maior resistência à cavitação. Além destes, a presença de tensões residuais compressivas, superfície lisa, maior resistência à corrosão e isotropia do material, são citados neste trabalho como fatores que incrementam a resistência à cavitação do material. Hattori e Ishikura [11] após compilarem resultados de ensaios de cavitação em diferentes aços inoxidáveis, concluem que a dureza e o aumento desta durante a erosão, possuem elevada correlação com a taxa de erosão por cavitação destes aços sejam estes laminados ou fundidos. Heathcock et al. [12] abordam aspectos relacionados ao desempenho à cavitação dos aços inoxidáveis. Tais autores destacam que resistência à erosão dos aços inoxidáveis martensíticos temperados e revenidos é diretamente proporcional à dureza. Tais autores ressaltam ainda que a presença de carbonetos grosseiros possui um efeito adverso na resistência à cavitação de tais aços haja vista a nucleação do desgaste ocorrer entre estes e a matriz devido a diferenças de módulo de elasticidade e plasticidade. Já com relação aos austeníticos, a resistência à cavitação destes está diretamente relacionada com o coeficiente de encruamento, ou seja, quanto maior este coeficiente, maior a resistência à cavitação desta classe de aços. Com relação aos aços inoxidáveis ferríticos, segundo estes autores, são os que apresentam menor resistência à cavitação dentre os aços inoxidáveis sendo que tal característica estaria associada à estrutura cristalina cúbica de corpo centrado destes em apresentar sensibilidade à altas taxas de deformação.

Supõe-se desta forma que alterações nas propriedades mecânicas e de corrosão promovidas pela formação da fase sigma em soldas do aço inoxidável austenítico possam influenciar no desempenho à cavitação. A abordagem realizada na literatura revela que pouco foi realizado com o objetivo de estudar a influência da fase sigma na resistência à cavitação de soldas de reparo de rotores de turbinas hidráulicas. Desta forma, este trabalho tem por objetivo esclarecer as questões em aberto sobre o comportamento ao desgaste erosivo pelo mecanismo de cavitação de soldas de reparo do aço AISI 309L apresentando diferentes frações em volume de fase sigma, procurando-se assim enfatizar a influência desta fase tipicamente deletéria na resistência à erosão por cavitação do material estudado.

\section{Materiais e Métodos}

Inicialmente faz-se a descrição de como foram obtidos os corpos-de-prova com e sem fase sigma por meio de soldagem e tratamentos térmicos. Em seguida, é apresentado o ensaio empregado para determinar o comportamento à erosão por cavitação e por fim, são relatados os ensaios e análises utilizados para caracterização microestrutural e mecânica do material soldado.

\subsection{Obtenção de corpos-de-prova}

Corpos-de-prova medindo 25×25×10 mm foram extraídos da superfície de um depósito de solda obtido a partir da deposição de três camadas sobrepostas medindo cada uma destas aproximadamente 150x100 mm. As camadas foram depositadas por meio de cordões usando processo MAG sobre uma placa de aço inoxidável AISI 304 com 12,5 mm de espessura. O metal de adição utilizado foi o AWS ER 309L $\varnothing 1,2 \mathrm{~mm}$. Demais parâmetros de soldagem adotados são apresentados na Tabela 1.

Tabela 1. Parâmetros da soldagem utilizados na obtenção dos corpos-de-prova.

\begin{tabular}{ccc}
\hline Parâmetros & Valores \\
Corrente Média & $224 \mathrm{~A}$ \\
Tensão Média & $25 \mathrm{~V}$ \\
Gás de proteção & $98 \% \mathrm{Ar}+2 \% \mathrm{O}_{2}$ & $7,0 \mathrm{~m} / \mathrm{min}$ \\
Velocidade Arame & $10 \mathrm{~mm} / \mathrm{s}$ \\
Velocidade Soldagem & $150{ }^{\circ} \mathrm{C}$ \\
Temperatura de interpasse & \\
\hline
\end{tabular}

Visando a formação de fase sigma, parte dos corpos-de-prova foi submetida a tratamento térmico a $850{ }^{\circ} \mathrm{C}$ durante 30 min e $8 \mathrm{~h}$ seguido de resfriamento ao ar sendo que o restante destes permaneceu na condição como soldada. Os tempos escolhidos 
bem como a identificação das amostras (conjunto de três corpos-de-prova) são apresentados na Tabela 2. Destaca-se que as condições do tratamento térmico foram baseadas no diagrama TTT (Tempo x Temperatura x Transformação) do aço AISI 309L disponível em [13].

Tabela 2. Identificação das amostras estudadas em função da condição de tratamento térmico para formação de fase sigma.

Condições de tratamento térmico Tipo de amostra estudada
Amostra sem tratamento (como soldada, sem fase sigma)
Amostra tratada para a condição de menor fração em volume formada de fase sigma
Amostra tratada para a condição de maior fração em volume formada de fase sigma
$850{ }^{\circ} \mathrm{C}-30$ min
$850{ }^{\circ} \mathrm{C}-8 \mathrm{~h}$

Na sequência, visando identificar e quantificar a formação de fase sigma bem como confirmar a composição química do material a ser submetido ao ensaio de cavitação, os corpos-de-prova foram submetidos a avaliação prévia via difratometria de raios- $x(D R X)$, microscopia ótica e microscopia eletrônica de varredura com análise química via técnica de espectroscopia de energia dispersiva de raios-X (MEV/EDS). A análise via DRX foi realizada utilizando radiação CuKa monocromática com potencial de $40 \mathrm{kV}$ e $20 \mathrm{~mA}$, com comprimento de onda $\lambda=1,5406$ Á. O intervalo de varredura foi entre $30^{\circ}$ a $120^{\circ}$ e a velocidade de varredura empregada foi de $1 \% \mathrm{~min}$. Para a revelação da microestrutura foi utilizado ataque eletrolítico a $2,5 \mathrm{~V}$ durante $30 \mathrm{~s}$ em solução aquosa saturada de $\mathrm{KOH}$. A quantificação da fase sigma foi realizada por meio da aquisição e processamento de imagens utilizando software ImageJ.

\subsection{Ensaio de cavitação}

O ensaio de cavitação por vibração ultrasônica foi realizado em água destilada e na configuração de modo de ensaio indireto conforme orientações da norma ASTM G32-10 [14]. Antes do ensaio, as amostras foram submetidas a acabamento superficial por meio de lixamento seguido de polimento em alumina $1 \mu \mathrm{m}$. Cada amostra era composta por um conjunto de três corpos-de-prova sendo cada um destes submetido à erosão por cavitação por um período total de cinco horas. Tal duração de ensaio foi suficiente para se evidenciar o estágio da máxima taxa de erosão na curva de perda de massa versus tempo de ensaio. A cada 20 minutos, a perda de massa dos corpos-de-prova era determinada em balança de precisão de 0,01 mg. Demais parâmetros utilizados na execução do ensaio são apresentados na Tabela 3.

Tabela 3. Parâmetros utilizados no do ensaio de cavitação.

\begin{tabular}{cc} 
Parâmetro & Condição \\
Frequência da vibração do sonotrodo & $20 \mathrm{kHz}$ \\
Amplitude da vibração & $50 \mu \mathrm{mm}$ \\
Profundidade de imersão das amostras em água destilada & $12 \pm 4 \mathrm{~mm}$ \\
Distância ponteira-amostra & $0,5 \mathrm{~mm}$ \\
Temperatura & $25 \pm 2{ }^{\circ} \mathrm{C}$ \\
\hline
\end{tabular}

Os resultados obtidos foram expressos na forma de curva de perda de massa acumulada versus tempo de ensaio. A partir dessa curva, foram levantados os seguintes parâmetros resultantes do ensaio de cavitação: período de incubação, período de incubação nominal e taxa máxima de erosão. A definição desses parâmetros obtidos pode ser encontrada nas ref. [14,15]. A fim de caracterizar a morfologia das regiões cavitadas e de transição entre as regiões cavitada e a não cavitada, análises via MEV/EDS foram realizadas após o ensaio de cavitação. Em complemento, as superfícies cavitadas foram também submetidas à análise via difratometria de raios-x (DRX).

\subsection{Ensaios e análises complementares}

As amostras foram ainda ensaiadas via dureza Vickers aplicando uma carga de 10 kgf e pelo ensaio de impacto Charpy [16] em temperatura ambiente. Após ensaio Charpy, realizado apenas nas amostras "sem tratamento" (sem fase sigma) e "850 ${ }^{\circ} \mathrm{C}-$ $8 \mathrm{~h}$ " (com maior quantidade de fase sigma), as superfícies fraturadas foram analisadas via MEV/EDS a fim de serem obtidas informações sobre os modos de fratura desenvolvidos.

\section{Resultados e Discussão}

As composições de cromo e níquel obtidas via MEV/EDS sobre a superfície do metal de solda são apresentadas na Tabela 4. Os resultados confirmam os valores destes elementos para o aço AISI 309L comprovando que o procedimento de soldagem adotado minimizou a influência do metal de base na composição química da superfície mais externa do depósito de solda. 
Tabela 4. Composições de cromo e níquel obtidas via MEV/EDS sobre a superfície do depósito de solda.

\begin{tabular}{ccc}
\hline Elemento Químico & Composição (\% peso) & Especificação (\% peso) $^{23-25}$ \\
Cromo & 24 & $12-14$ \\
Níquel & 13 & 12 \\
\hline
\end{tabular}

${ }^{1}$ Especificação do metal de solda para o aço AISI 309L conforme norma AWS A5.9 [17].

As Figuras 1a-c apresentam as microestruturas das superfícies das amostras, reveladas com ataque específico para identificação de ferrita delta e fase sigma. A microestrutura da amostra "sem tratamento" (Figura 1a) apresentou 7,4 $\pm 0,7 \%$ de ferrita em matriz austenita, livre de fase sigma. Tal valor de ferrita delta se enquadra entre e 5 e $10 \%$ conforme diagrama de Schaeffler apresentado em [18] sendo este considerado adequado no que diz respeito à baixa probabilidade de ocorrência de trincas de solidificação. Já as amostras tratadas termicamente (Figuras 1b e 1c), apresentaram fase sigma conforme a quantidade indicada na Tabela 5, mostrando o aumento dessa fase com o aumento do tempo de tratamento térmico a $850^{\circ} \mathrm{C}$. Destaca-se que mesmo após $8 \mathrm{~h}$ a $850^{\circ} \mathrm{C}$ não ocorreu total transformação da ferrita delta em fase sigma. Segundo Folkhard [13] devido ao alto teor de cromo e baixo teor de níquel da fase sigma, ocorre redução de cromo e aumento de níquel na ferrita delta residual sendo esta transformada em austenita secundária, justificando assim a incompleta transformação da ferrita delta em sigma.

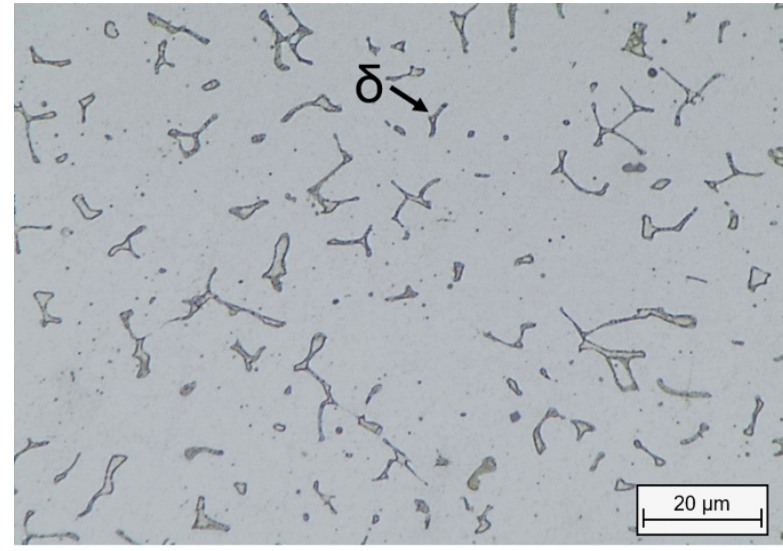

(a)

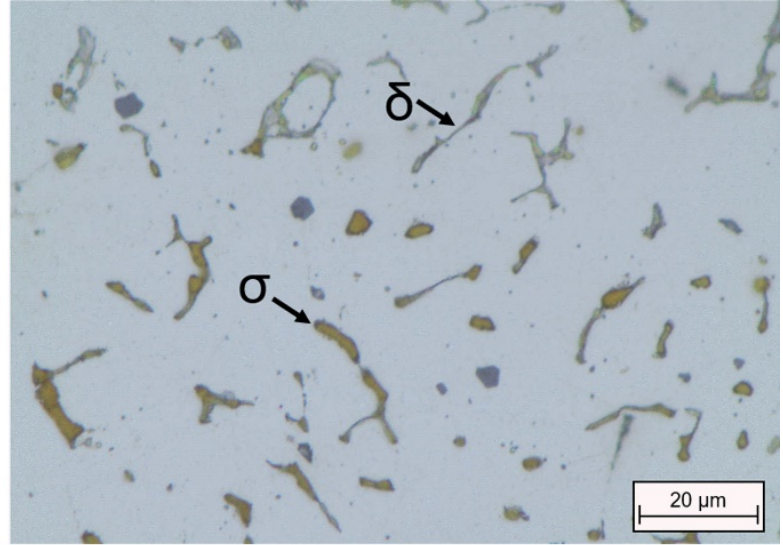

(b)

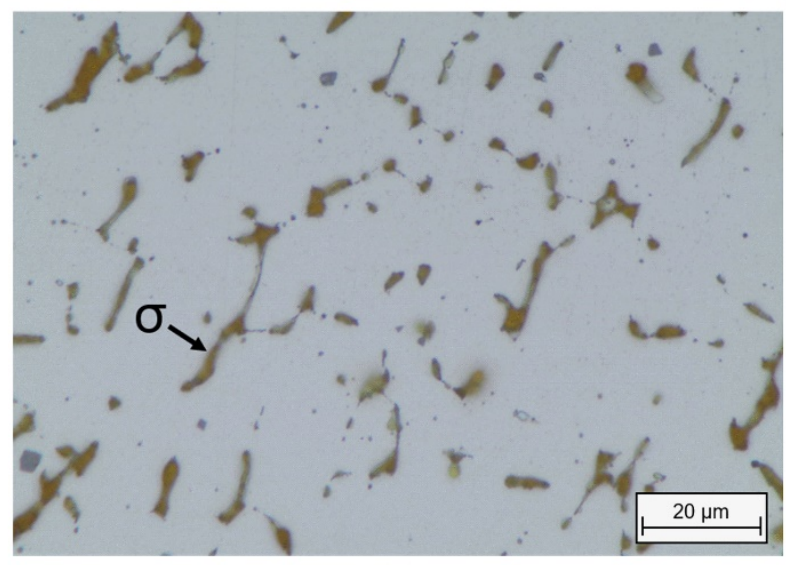

(c)

Figura 1. Micrografias das amostras com ampliação de 1000 x sobre a superfície, revelando a distribuição da ferrita delta ( $\delta)$ e da fase sigma

( $\sigma)$ na matriz austenítica. (a) amostra sem tratamento. (b) amostra com tratamento à $850^{\circ} \mathrm{C}$ por $30 \mathrm{~min}$. (c) amostra com tratamento térmico à $850^{\circ} \mathrm{C}$ por $8 \mathrm{~h}$. Ataque eletrolítico $\mathrm{KOH}$.

Tabela 5. Porcentagem de precipitação de fase sigma.

\begin{tabular}{cc}
\hline amostra & \% de precipitação ${ }^{1}$ \\
sem tratamento & $0,0 \pm 0,0$ \\
$850^{\circ} \mathrm{C}-30$ min & $2,7 \pm 0,7$ \\
$850^{\circ} \mathrm{C}-8 \mathrm{~h}$ & $5,8 \pm 0,4$ \\
\hline
\end{tabular}

${ }^{1}$ intervalo de confiança $=95 \%$ 


\subsection{Comportamento à erosão por cavitação}

Segundo a norma ASTM G32-10 [14], a resistência à erosão por cavitação pode ser caracterizada quantitativamente em função de seu período de incubação e de sua taxa de erosão máxima. O primeiro parâmetro representa o acúmulo de deformação plástica e tensões internas sob a superfície que precede a perda de material (taxa de erosão igual a zero) e o segundo, a ocorrência de um valor máximo típico dos ensaios de cavitação que perdura por um determinado tempo. Quanto menor o período de incubação e maior a taxa de erosão máxima, menor a resistência à erosão por cavitação.

A Figura 2 apresenta a evolução da perda massa acumulada média em função do tempo no ensaio de cavitação para todas as amostras. Constata-se que a amostra "sem tratamento", sem fase sigma, exibiu a menor perda de massa acumulada média no final do ensaio $(4,95 \pm 0,34 \mathrm{mg})$. No outro extremo, a amostra " $850^{\circ} \mathrm{C}-8 \mathrm{~h}$ ", com maior quantidade de fase sigma, apresentou a maior perda de massa acumulada $(7,52 \pm 0,22 \mathrm{mg})$, seguida da amostra “ $850^{\circ} \mathrm{C}-30 \mathrm{~min}$ " $(5,68 \pm 0,22 \mathrm{mg})$.

A duração de $5 \mathrm{~h}$ do ensaio foi o suficiente para atingir o estágio de máxima taxa de erosão. Com isso foi possível obter os períodos de incubação, de incubação nominal e a taxa de erosão máxima conforme apresentados na Figura 3. Considerando os valores médios, o maior período de incubação $(2,7 \mathrm{~h})$ e a menor taxa de erosão máxima $(2,7 \mathrm{mg} / \mathrm{h})$ foram encontrados na amostra "sem tratamento". Por outro lado, o pior desempenho foi da amostra " $850{ }^{\circ} \mathrm{C}-8 \mathrm{~h}$ " que apresentou o menor período de incubação $(0,6 \mathrm{~h})$ e a maior taxa de erosão máxima $(3,5 \mathrm{mg} / \mathrm{h})$. Tais variações correspondem a uma redução de $78 \%$ no período de incubação e um aumento de $30 \%$ na taxa de erosão máxima em relação a amostra "sem tratamento". A amostra “850 ${ }^{\circ} \mathrm{C}$ - 30 min", por sua vez, apresentou um desempenho intermediário em relação à taxa de erosão máxima, contudo, um período de incubação similar à amostra "sem tratamento". Supõe-se que, além da menor quantidade, a fase sigma formada nesta amostra seja resultante de uma menor quantidade de cromo difundida para esta e portanto, uma menor depleção deste elemento em áreas de ferrita e austenita adjacentes e daí um comportamento intermediário.

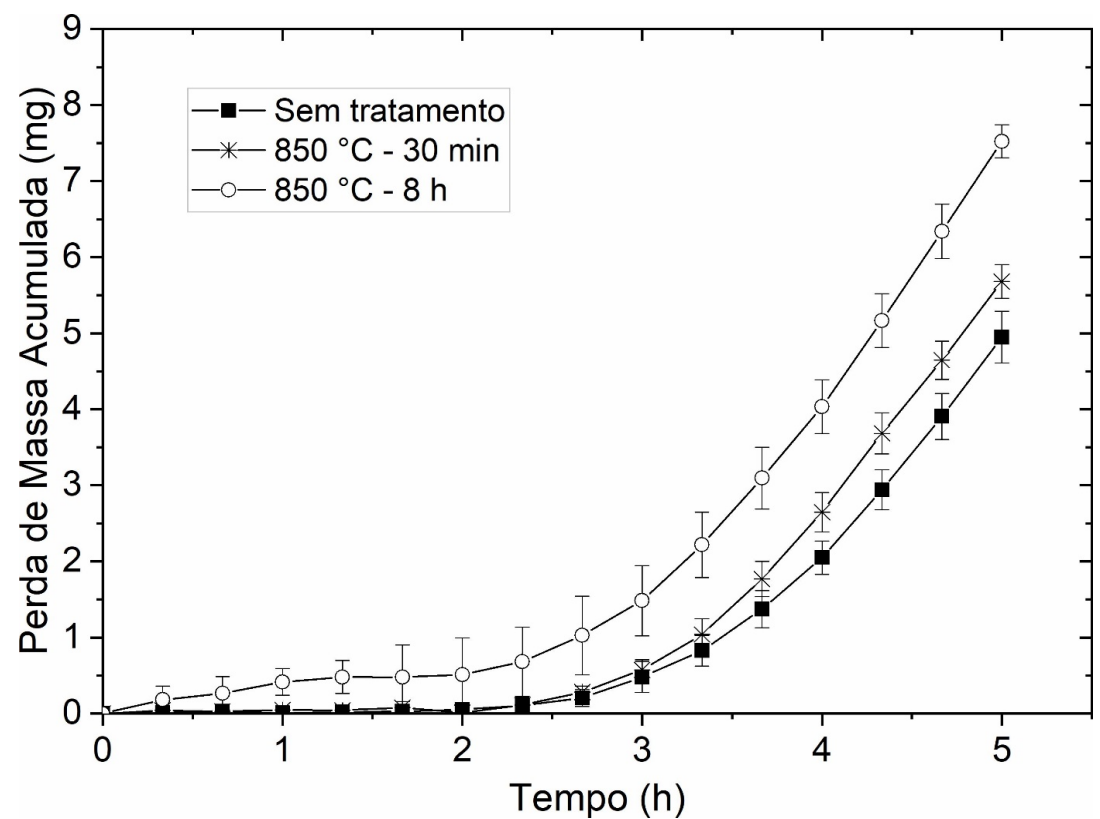

Figura 2. Curvas de perda de massa acumulada vs. tempo de ensaio obtidas no ensaio de cavitação.

Em relação ao estágio de incubação, vale mencionar que na Figura 3 são apresentados os períodos de incubação e de incubação nominal separadamente, os quais se diferenciam pelo método de obtenção. O período de incubação foi determinado por meio do critério de "perda de massa nula", adotando uma compensação arbitrária, segundo a qual qualquer perda de massa abaixo de 0,20 mg foi considerada irrelevante. Por sua vez, o período de incubação nominal foi estimado graficamente a partir da inclinação da parte reta da curva de perda de massa cumulativa na sua região de máxima taxa de erosão, conforme previamente descrito nas ref. [14,15].

O valor do período de incubação tende a ser relativamente menor que o do período de incubação nominal, como mostra a Figura 3. A diferença entre esses valores foi igual para as amostras nas condições "sem tratamento" e " $850{ }^{\circ} \mathrm{C}-30$ min" $(0,5 \mathrm{~h})$. Porém, a amostra " $850^{\circ} \mathrm{C}-8 \mathrm{~h}$ " apresentou uma diferença superior a quatro vezes $(2,2 \mathrm{~h})$ em relação às demais, o que indica, que para esta amostra ocorreu uma maior predisposição ao desgaste induzido pela maior quantidade de fase sigma. Em relação à máxima taxa de erosão, constata-se a tendência desta apresentar um maior valor com o aumento da quantidade de fase sigma. 

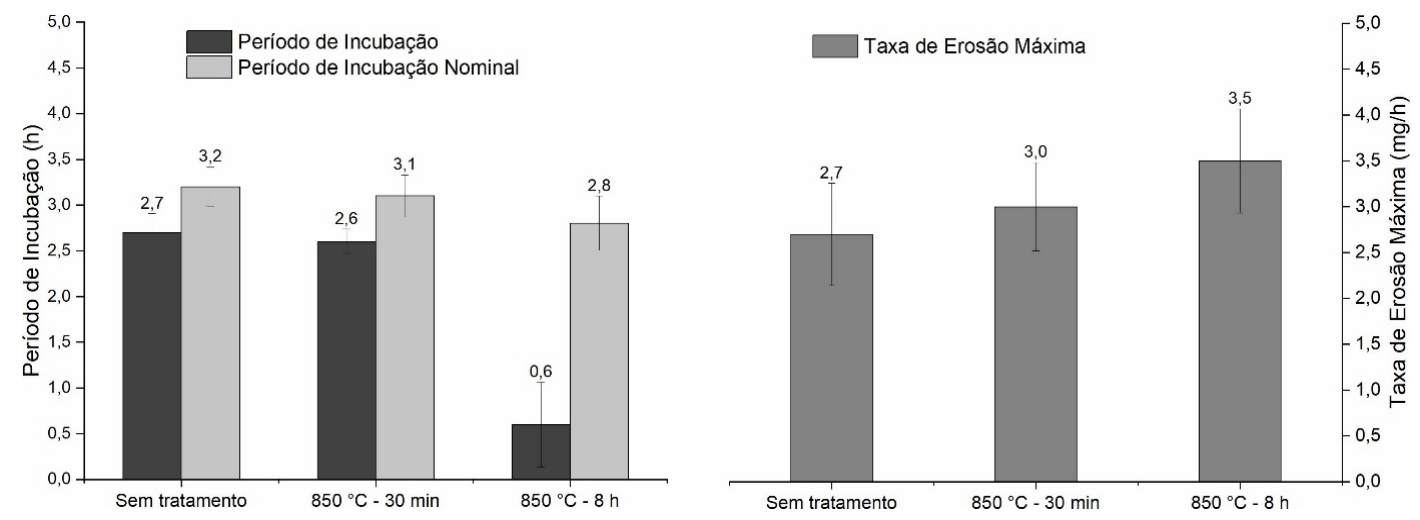

Figura 3. Períodos de incubação e taxas de erosão máxima de cavitação das amostras.

\subsection{Ensaios e análises complementares}

A Figura 4 apresenta os resultados de ensaio Charpy obtidos nas amostras "sem tratamento" e " $850{ }^{\circ} \mathrm{C}-8 \mathrm{~h}$ " bem como valores de dureza média dos três tipos de amostras estudados. Baixos teores de fase sigma promovem uma diminuição considerável da tenacidade sem influência significativa na dureza. Constata-se que a energia absorvida no ensaio Charpy da amostra " $850^{\circ} \mathrm{C}-8 \mathrm{~h}$ " foi comprometida pela presença da fase sigma em aproximadamente $50 \%$ em comparação aos valores obtidos na amostra "sem tratamento". Em relação aos resultados de dureza, não houve variação significativa em função da presença da fase sigma para as três amostras. Resultados similares de resistência ao impacto e dureza foram obtidos por [19-21] em aços inoxidáveis duplex. Segundo Nilsson et al. [21] são necessários pelo menos $10 \%$ de fase sigma para dar um aumento substancial de dureza ao material. Essa ausência de variação da dureza pode justificar os valores próximos de incubação nominal (Figura 3) entre as amostras, já que a dureza possui relação direta com o período de incubação [22].
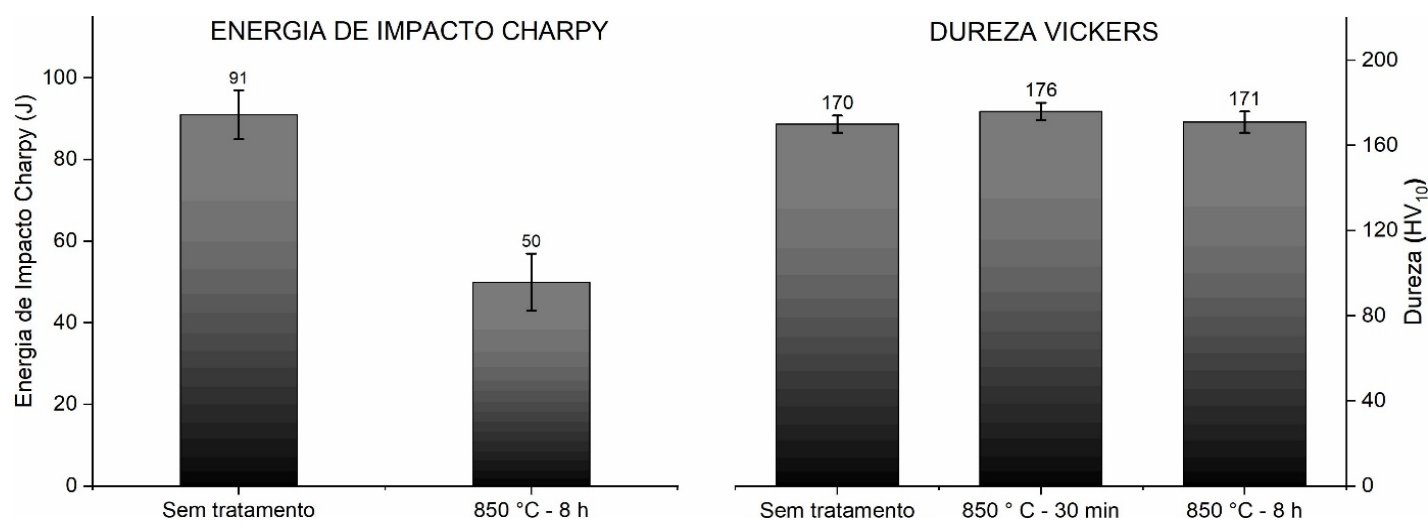

Figura 4. Energia absorvida durante ensaio de impacto Charpy e dureza das amostras.

As Figuras 5a-d ilustram as superfícies de fratura dos corpos-de-prova Charpy com e sem fase sigma. Percebe-se macroscopicamente, que a amostra "sem tratamento" apresenta uma superfície rugosa, de menor brilho e com maior deformação lateral em relação à amostra " $850^{\circ} \mathrm{C}-8 \mathrm{~h}$ ". Tanto a maior deformação lateral, bem como a maior rugosidade e menor brilho da amostra "sem tratamento", vem corroborar o maior valor de energia absorvida no ensaio de impacto Charpy em relação à amostra " $850^{\circ} \mathrm{C}-8 \mathrm{~h}$ ".

Quando analisadas microscopicamente via MEV, foram identificados dimples característicos de fratura dúctil em ambas as amostras, sendo que na amostra " $850^{\circ} \mathrm{C}-8 \mathrm{~h}$ ", além de dimples, foram também constatadas regiões planas apresentando morfologia típica de fratura por quase-clivagem. Tal morfologia, bem como a baixa tenacidade ao entalhe da amostra " $850{ }^{\circ} \mathrm{C}$ $8 \mathrm{~h}$ ", ao que tudo indica, segundo trabalho de Chen et al. [23] envolvendo metal de solda de AISI 316L, estariam associadas à formação e crescimento de microtrincas junto à fase sigma quando submetida à deformação, devido à fragilidade da mesma. Segundo estes mesmos autores, a ferrita delta, pelo contrário, tenderia a se deformar plasticamente ao invés de trincar.

As Figuras 6a-d, ilustram as morfologias das superfícies cavitadas das amostras com e sem fase sigma analisadas via MEV. Com baixa ampliação, constata-se na amostra " 850 C - $8 \mathrm{~h}$ ", quando comparada à condição de amostra "sem tratamento", um aspecto mais rugoso e uma maior quantidade de regiões isoladas identificadas como "crateras". Quando analisadas com maior ampliação, constatou-se que a morfologia das "crateras" era similar à das regiões identificadas como quase-clivagem apresentadas na Figura $5 \mathrm{~d}$. Tal constatação pressupõe que a solicitação imposta ao material pela ação dos microjatos durante o ensaio de cavitação, seja semelhante à do impacto desenvolvido no ensaio Charpy. Considera-se, portanto, que a diferença 
média de $30 \%$ observada na taxa de erosão máxima entre as amostras "sem tratamento" e " $850{ }^{\circ} \mathrm{C}-8 \mathrm{~h}$ " (Figura 3) seria justificada pela diminuição da tenacidade do material, causada pela presença da fase sigma.

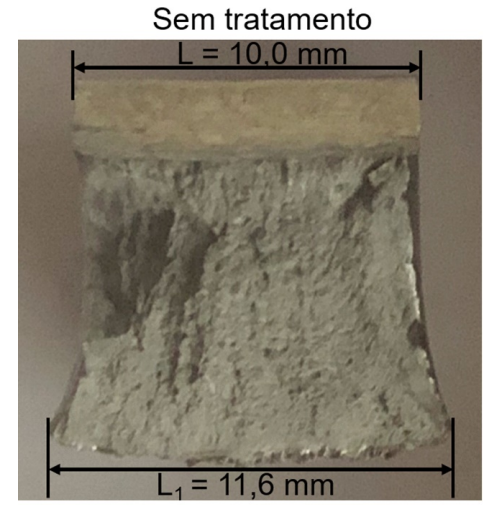

(a)

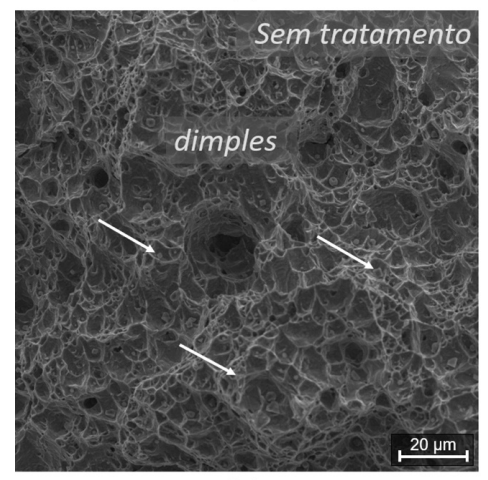

(c)

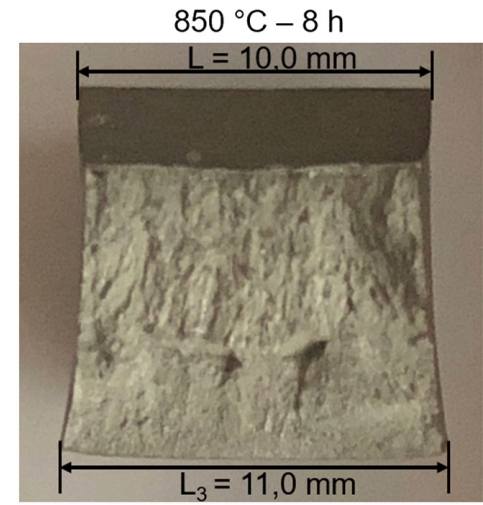

(b)

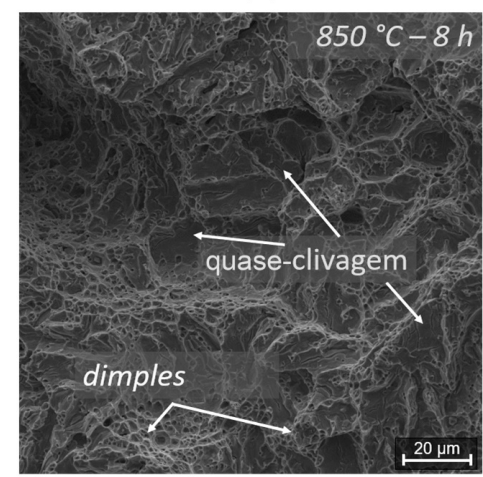

(d)

Figura 5. Superfícies de fratura das amostras "sem tratamento" (a-c) e "850 ${ }^{\circ} \mathrm{C}-8 \mathrm{~h}$ " (b-d) após ensaio de impacto Charpy. (a-b) macroscópica (c-d) microscópica via MEV.

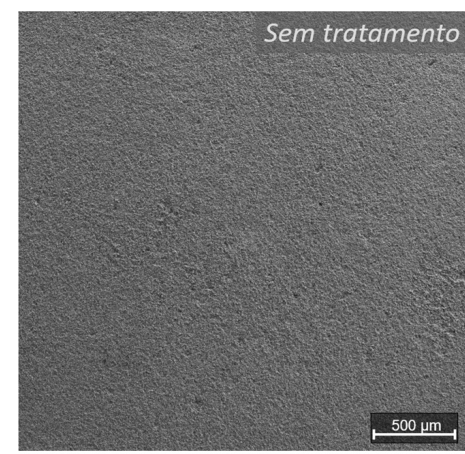

(a)

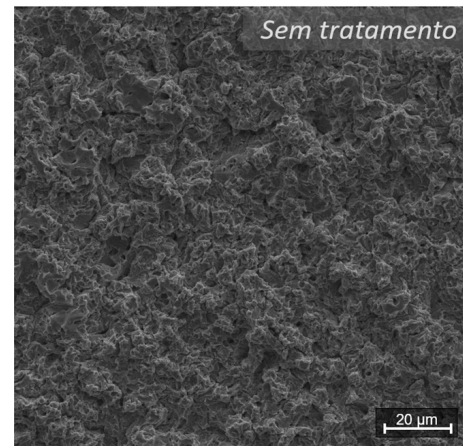

(c)

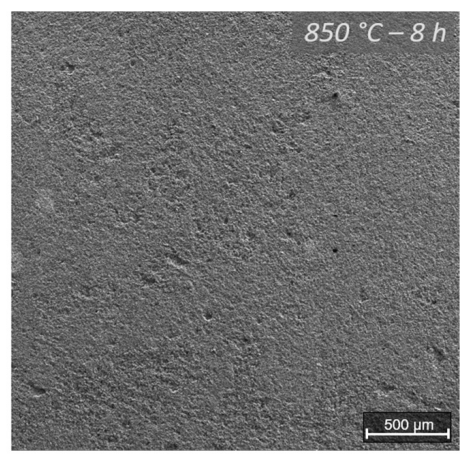

(b)

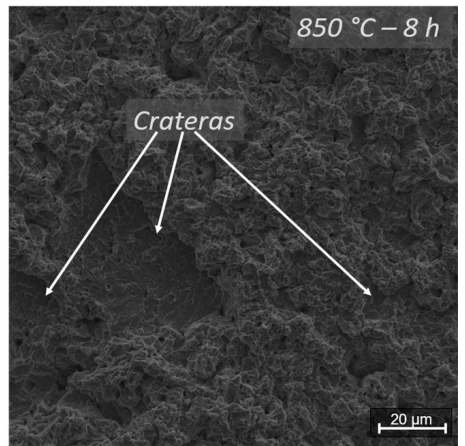

(d)

Figura 6. Região central cavitada das amostras "sem tratamento" (a-c) e " $850^{\circ} \mathrm{C}-8 \mathrm{~h}$ " (b-d); (a-b) Aumento de $100 x$ e (c-d) Aumento de 2000x. 
Nas Figuras 7a e 7b são mostrados os difratogramas obtidos nas superfícies das amostras antes e após ensaio de cavitação. Com base nos resultados obtidos, constata-se que em nenhuma amostra ocorreu transformação de fase induzida pela cavitação. Em compensação, foi identificada uma redução na intensidade dos picos de fase sigma indicando que esta fase foi preferencialmente removida da superfície durante a ação erosiva imposta pelo ensaio de cavitação. Tal fato pode ser justificado considerando-se a fase sigma ser menos tenaz que a matriz austenítica, e desta forma, ser removida preferencialmente desta contribuindo para o aumento da taxa de erosão.

Foi constatado ainda, conforme detalhe na Figura 7c, que somente a amostra "sem tratamento" apresentou os picos de difração deslocados à esquerda dos picos padrões identificados nas outras amostras. A explicação para tal deslocamento, ao que tudo indica, estaria associada à presença de tensões residuais trativas, haja vista não ser realizado tratamento térmico de alívio de tensões nesta amostra. Tais tensões trativas, contribuem para o desgaste erosivo [10], porém, supostamente tendem a diminuir com a imposição de esforços compressivos resultantes dos colapsos das bolhas de cavitação, visto que os deslocamentos dos picos diminuíram após a realização do ensaio erosivo.

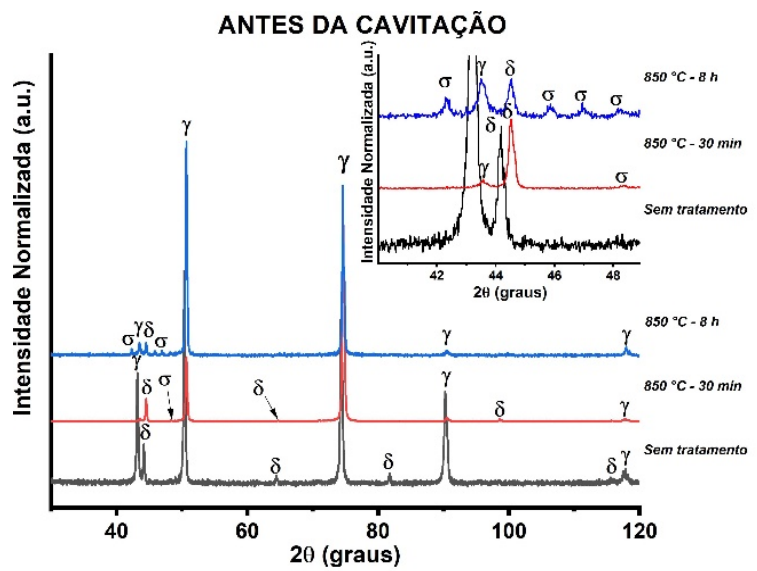

(a)

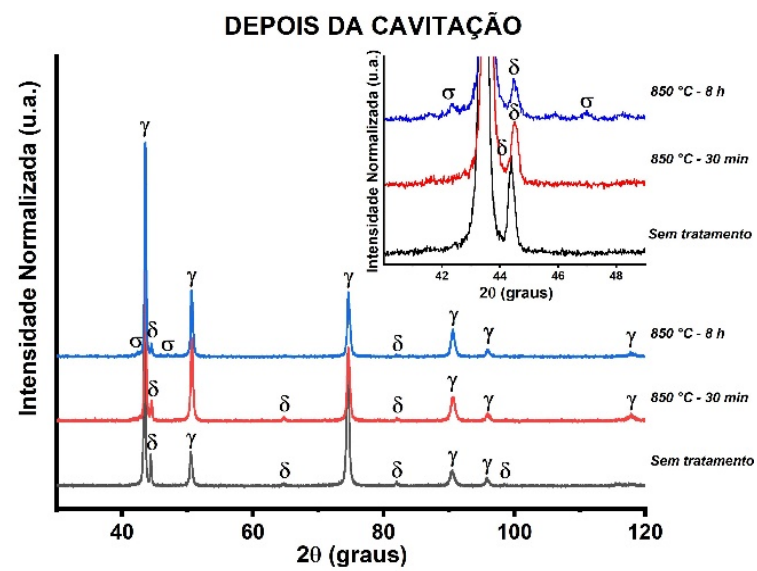

(b)

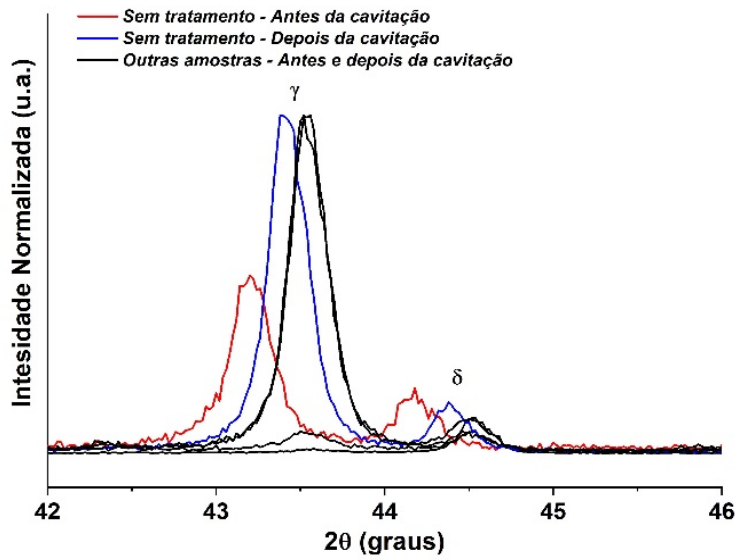

(c)

Figura 7. Difratogramas (a) antes do ensaio de cavitação, (b) após ensaio de cavitação e (c) sobreposição dos difratogramas, antes e após ensaio de cavitação, destacando o deslocamento à esquerda dos picos da amostra "sem tratamento" nas duas condições.

As Figuras 8a-c obtidas por MEV ilustram as regiões de transição cavitada e não cavitada das condições de amostras "sem tratamento" e "850 ${ }^{\circ} \mathrm{C}-8 \mathrm{~h}$ " bem como mapeamento por EDS do elemento cromo. Nessa região intermediária é possível avaliar as etapas iniciais da cavitação. Constatou-se que na amostra "sem tratamento" e portanto, sem fase sigma, o início da cavitação ocorre preferencialmente sobre as regiões de ferrita delta. Segundo Heathcock et al. [12] a menor resistência à cavitação da fase ferrítica em relação à austenítica, estaria relacionada à estrutura cúbica de corpo centrado da ferrita em apresentar maior sensibilidade a altas taxas de deformação. Já na amostra " $850{ }^{\circ} \mathrm{C}-8 \mathrm{~h}$ ", foi identificado o início do processo erosivo a partir da interface austenita-sigma. A erosão nessa região ao que tudo indica, seria consequência da diferença acentuada da dureza e da ductilidade entre a fase sigma e a matriz. De forma similar, Heathcock et al. [12] constataram tal mecanismo de nucleação quando da avaliação da resistência à cavitação de um aço inoxidável martensítico contendo carbonetos grosseiros sendo o mesmo considerado de efeito adverso em relação à resistência à cavitação de um aço da mesma classe, porém, com carbonetos 
refinados. Espera-se desta forma justificar a redução do período de incubação desta amostra em relação à amostra sem fase sigma.

Similarmente, a acentuada queda da tenacidade do material promovida pela presença da fase sigma na amostra " $850{ }^{\circ} \mathrm{C}$ - 8 h", corrobora a maior taxa de erosão máxima encontrada neste material evidenciando que a presença da fase sigma exerce influência negativa em ambas as etapas da cavitação, tanto na redução do período de incubação bem como ainda elevando a taxa de erosão máxima.
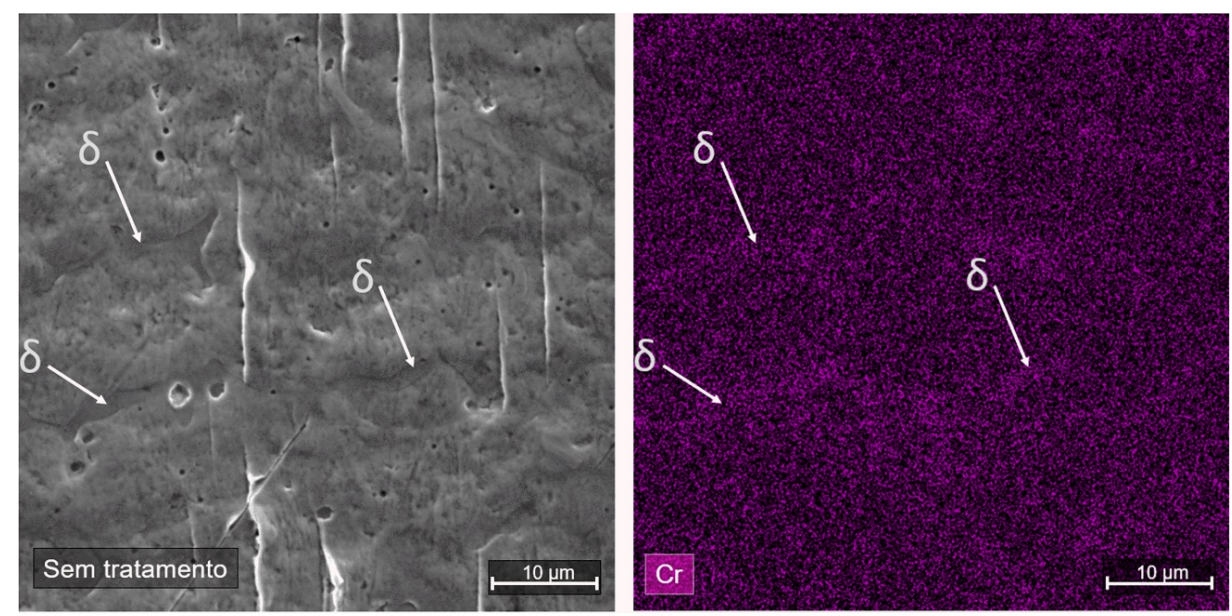

(a)

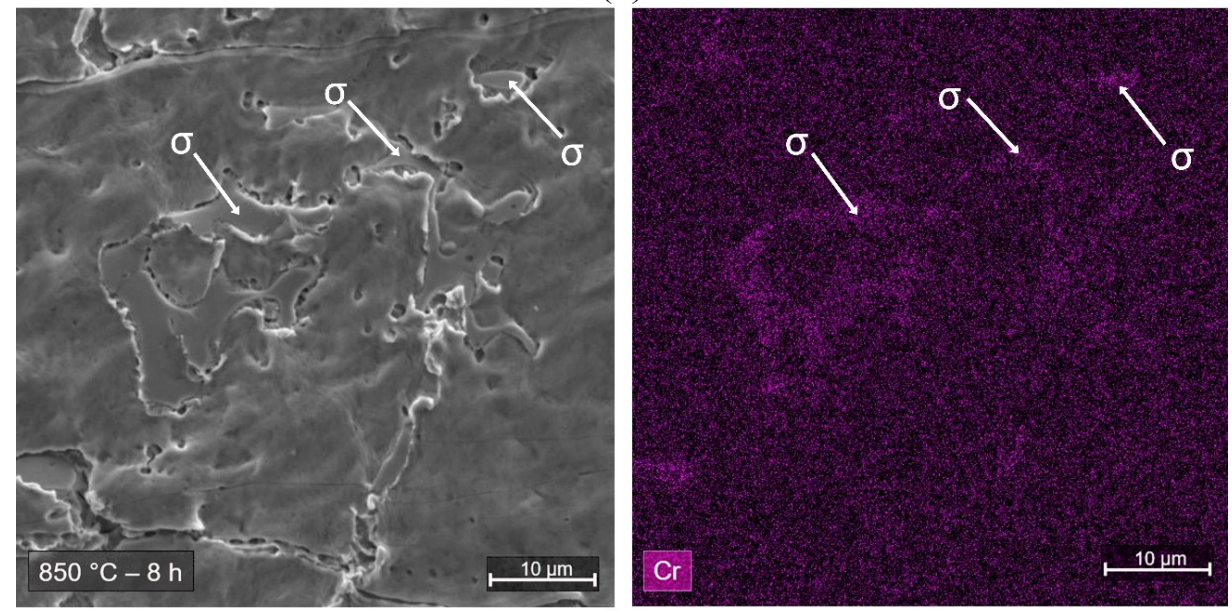

(b)
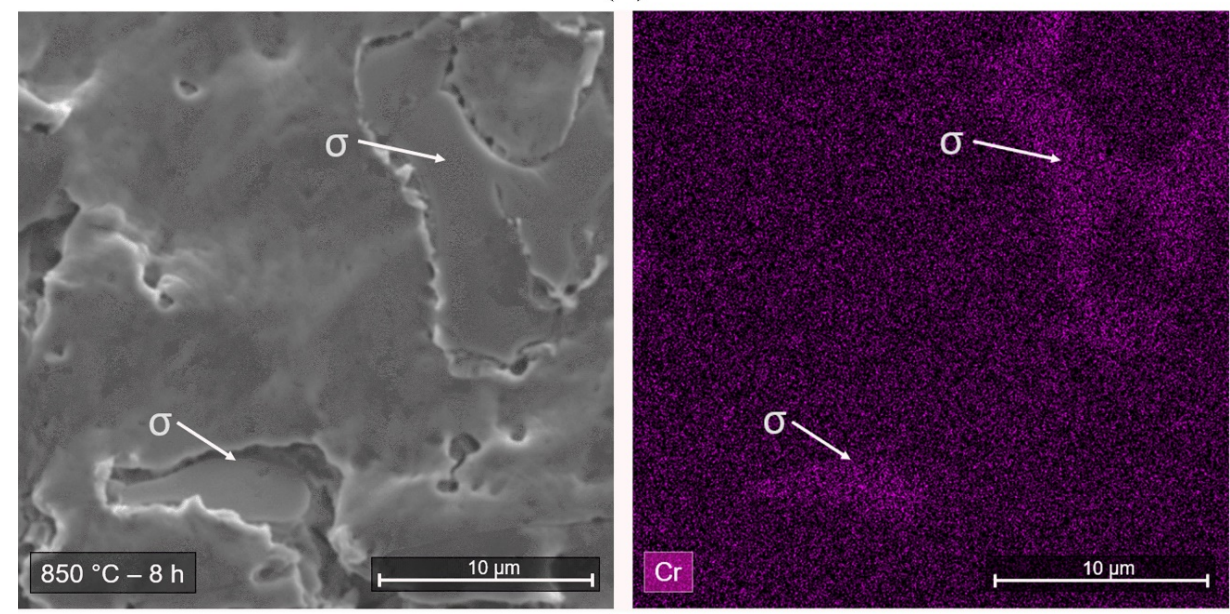

(c)

Figura 8. Regiões de transição entre as superfícies cavitada e não cavitada e o mapeamento por EDS do elemento Cr. (a) amostra "sem tratamento" destacando regiões com ferrita delta; (b) amostra " $850^{\circ} \mathrm{C}-8 \mathrm{~h}$ " revelando o início do processo de erosão na interface austenita-sigma. (c) detalhe da figura b com maior ampliação. 


\section{Conclusão}

Com base nos resultados obtidos, é possível concluir o seguinte:

- A presença de uma fração volumétrica de 5,8\% de fase sigma precipitada no metal de solda do aço AISI 309L resultou em uma significativa redução da resistência à erosão por cavitação deste metal para esta condição de estudo, o qual apresentou uma redução de $78 \%$ para o seu período de incubação e um aumento de $30 \%$ para a sua taxa máxima de erosão em relação ao metal de solda sem esta fase.

- Infere-se que a redução expressiva do período de incubação decorrente da presença da fase sigma, a princípio, seria consequência da diferença acentuada de propriedades mecânicas entre esta fase e a matriz austenítica haja vista a constatação do início do processo de cavitação na interface das mesmas.

- A diminuição da tenacidade do material promovida pela fase sigma, ainda que sem alteração significativa na dureza, resultou no aumento da taxa de erosão máxima reduzindo a resistência à cavitação do material.

\section{Agradecimentos}

Este trabalho foi apoiado pela CAPES (Coordenação de Aperfeiçoamento de Pessoal de Nível Superior - Brasil - Código Financeiro 001). Um dos autores, Professor Silvio F. Brunatto, também agradece ao CNPq, CNPq (Projeto Universal no 482380 / 2012-8), MCTI (MCTI / CNPq / CT-Aquaviário Projeto no 456347 / 2013-5) e Fundação Araucária do Estado do Paraná (PRONEX Projeto $\mathrm{n}$ - 46744) pelo apoio financeiro. Os autores também desejam expressar seus agradecimentos ao Laboratório de Ótica e Instrumentação de Raios X - LORXI e ao Centro de Microscopia Eletrônica (CME) da Universidade Federal do Paraná (UFPR) pela utilização dos equipamentos de DRX e MEV, respectivamente.

\section{Referências}

[1] Agência Nacional de Energia Elétrica - ANEEL. Sistema de Informações de Geração: SIGA. Brasília: ANEEL; 2020. [acesso em 29 ago. 2020]. Disponível em: https://bit.ly/2IGf4Q0.

[2] International Hydropower Association. Hydropower around the world. London: International Hydropower Association; 2020. [acesso em 26 dez. 2020]. Disponível em: Disponível em. https://www.hydropower.org/discover/hydropower-around-the-world

[3] Arndt REA, Voigt RL Jr, Sinclair JP, Rodrique P, Ferreira A. Cavitation erosion in hydroturbines. Journal of Hydraulic Engineering. 1989;115(10):1297-1315. http://dx.doi.org/10.1061/(ASCE)0733-9429(1989)115:10(1297).

[4] Kou S. Welding metallurgy. 2nd ed. Hoboken: John Wiley \& Sons, Inc.; 2003.

[5] Lippold JC, Kotecki DJ. Welding metallurgy and weldability of stainless steels. Hoboken: John Wiley \& Sons, Inc.; 2005.

[6] Tseng CC, Shen $Y$, Thompson SW, Mataya MC, Krauss G. Fracture and the formation of sigma phase, $M_{23} C_{6}$, and austenite from deltaferrite in an AISI 304L stainless steel. Metallurgical and Materials Transactions. A, Physical Metallurgy and Materials Science. 1994;25(6):1147-1158. http://dx.doi.org/10.1007/BF02652290.

[7] Kim IS, Lee JS, Kimura A. Embrittlement of ER309L stainless steel clad by $\sigma$-phase and neutron irradiation. Journal of Nuclear Materials. 2004;329:607-611. http://dx.doi.org/10.1016/j.jnucmat.2004.04.104.

[8] Kuboň Z, Stejskalová Š, Kander L. Effect of sigma phase on fracture behavior of steels and weld joints of components in power industry working at supercritical conditions. In: Borek W, Tański T, Brytan Z, editors. Austenitic Stainless Steels: New Aspects. Rijeka: IntechOpen; 2017. p. 63-92.

[9] Guilherme LH, Benedetti AV, Fugivara CS, Magnabosco R, Oliveira MF. Effect of MAG welding transfer mode on sigma phase precipitation and corrosion performance of $316 \mathrm{~L}$ stainless steel multi-pass welds. Journal of Materials Research and Technology. 2020;9(5):10537-10549. http://dx.doi.org/10.1016/j.jmrt.2020.07.039.

[10] Zakrzewska DE, Krella AK. Cavitation erosion resistance - influence of material properties. Advances in Materials Science. 2019;19(4):1834. http://dx.doi.org/10.2478/adms-2019-0019.

[11] Hattori S, Ishikura R. Revision of cavitation erosion database and analysis of stainless steel data. Wear. 2010;268(1-2):109-116. http://dx.doi.org/10.1016/j.wear.2009.07.005.

[12] Heathcock CJ, Protheroe BE, Ball A. Cavitation erosion of stainless steels. Wear. 1982;81(2):311-327. http://dx.doi.org/10.1016/00431648(82)90278-2.

[13] Folkhard E. Welding metallurgy of stainless steels. 1st ed. New York: Spring-Verlag; 1988. http://dx.doi.org/10.1007/978-3-7091-8965-8.

[14]American Society for Testing and Materials - ASTM. ASTM G32-10. Standard Test Method for Cavitation Erosion Using Vibratory Apparatus. West Conshohocken: ASTM International; 2010.

[15] Brunatto SF, Allenstein AN, Allenstein CLM, Buschinelli AJA. Cavitation erosion behaviour of niobium. Wear. 2012;274-275:220-228. http://dx.doi.org/10.1016/j.wear.2011.09.001. 
[16]American Society for Testing and Materials - ASTM. ASTM E23-02. Standard Test Methods for Notched Bar Impact Test of Metallic Materials. West Conshohocken: ASTM International; 2002.

[17]American Welding Society - AWS. AWS A5.9. Specification for Bare Stainless Steel Welding Electrodes and Rodes. Miami: HIS; 2006.

[18] Elias MS, Paranhos R. Avaliação metalúrgica da soldagem de revestimento inox austenítico sobre aço SAE 4130. Soldagem e Inspeção. 2014;19(4):343-352. http://dx.doi.org/10.1590/0104-9224/SI1904.07.

[19] Tavares SSM, Pardal JM, Guerreiro JL, Gomes AM, Silva MR. Magnetic detection of sigma phase in duplex stainless steel UNS S31803. Journal of Magnetism and Magnetic Materials. 2010;322(17):L29-L33. http://dx.doi.org/10.1016/j.jmmm.2010.02.055.

[20] Chen TH, Weng KL, Yang JR. The effect of high-temperature exposure on the microstructural stability and toughness property in a 2205 duplex stainless steel. Materials Science and Engineering. 2002;338(1-2):259-270. http://dx.doi.org/10.1016/S0921-5093(02)00093-X.

[21] Nilsson J-O, Kangas P, Wilson A, Karlsson T. Mechanical properties, microstructural stability and kinetics of s-phase formation in $29 \mathrm{Cr}-$ $6 \mathrm{Ni}-2 \mathrm{Mo}-0.38 \mathrm{~N}$ superduplex stainless steel. Metallurgical and Materials Transactions. A, Physical Metallurgy and Materials Science. 2000;31(1):35-45. http://dx.doi.org/10.1007/s11661-000-0050-1.

[22] He J-G, Hammitt FG. Comparison of cavitation erosion test results from venturi and vibratory facilities. Wear. 1982;76(3):269-292. http://dx.doi.org/10.1016/0043-1648(82)90067-9.

[23] Chen H, Li J, Cheng X, Wang H, Huang Z. Effect of heat treatment on microstructure, mechanical and corrosion properties of austenitic stainless steel 316L using arc additive manufacturing. Materials Science and Engineering A. 2018;715:307-314.

http://dx.doi.org/10.1016/j.msea.2017.10.002. 